\title{
Dispersion of High Concentrations of Carbon Nanofibers in Portland Cement Mortars
}

\author{
Joshua Hogancamp and Zachary Grasley \\ Department of Civil Engineering, Texas A\&M University, College Station, TX, USA \\ Correspondence should be addressed to Zachary Grasley; zgrasley@tamu.edu
}

Received 25 September 2016; Revised 2 March 2017; Accepted 20 March 2017; Published 5 April 2017

Academic Editor: Albert Nasibulin

Copyright (C) 2017 Joshua Hogancamp and Zachary Grasley. This is an open access article distributed under the Creative Commons Attribution License, which permits unrestricted use, distribution, and reproduction in any medium, provided the original work is properly cited.

\begin{abstract}
This research focuses on creating and maintaining a stable dispersion of carbon nanofibers (CNFs) in portland cement based materials. A microfine cement is used in conjunction with an untraditional dispersion method to encourage and stabilize the dispersion of CNFs in concentrations up to $5 \%$ by mass of cement. A computational simulation was utilized to examine an effect called geometric clustering on the dispersion of CNFs among Type I/II and microfine cement grains. The geometric clustering simulation revealed a higher achievable dispersion for microfine cement than for Type I/II cement. Scanning electron microscopy (SEM) was used to quantify the dispersion of CNFs among Type I/II and microfine cement grains. SEM image analysis indicated excessive CNF clumping among Type I/II cement grains, while the dispersion of hybrid microfine cement mortar continued to improve as the concentration of CNFs increased up to 5\% by mass of cement. Mortar cube elastic stiffness and mortar prism flexure tests revealed that high concentrations of CNFs had detrimental effects in hybrid Type I/II cement mortar, whereas similar concentrations of CNFs had negligible or beneficial effects in hybrid microfine cement mortar.
\end{abstract}

\section{Introduction}

In the past decade, researchers focused on portland cement based materials (PCBMs) have been attempting to incorporate carbon nanofibers (CNFs) and carbon nanotubes (CNTs) into cement paste, mortar, and concrete to create a composite with enhanced mechanical, electrical, and thermal properties [1-10]. The susceptibility of nanoparticles and nanofibers to thermal effects and van der Waals' forces, especially in water where CNFs and CNTs display hydrophobic tendencies, creates a ubiquitous hindrance to successfully incorporating CNFs and CNTs into PCBMs. The nanoparticles readily agglomerate together to form clumps on the order of micrometers or millimeters that lead to inconsistent material properties and potentially diminished material strength and stiffness [11-16]. Sonicating the CNFs in an aqueous solution of the PCBM mix water with a surfactant such as superplasticizer is the most common procedure to attempt to create a uniform distribution of CNFs in cement paste; the surfactant decreases or eliminates the hydrophobic tendencies of CNFs, and the sonication disentangles and disperses the CNFs [6, 17-19]. However, evidence of CNF and CNT clumps in hydrated cement paste samples suggests that a uniform dispersion of CNFs in the mix water does not guarantee a uniform dispersion of CNFs in the hydrated cement paste [20]. One mechanism of the CNF agglomeration is the free movement of CNFs between cement grains before the cement hydrates [21]; another mechanism is the apparent agglomeration of CNFs in aqueous solutions with a $\mathrm{pH}$ in excess of 10 (such as cement pore water) [22]; a third mechanism is compaction efforts (such as vibration) in conjunction with the previous two mechanisms further encouraging the agglomeration of CNFs in the fresh cement paste.

There are currently two primary methods identified in the literature to discourage $\mathrm{CNF}$ agglomeration and the movement of CNF bundles through the fresh paste. The first method is to use concentrations of nanofibers as low as $0.048 \%$ by mass of cement or $0.10 \%$ by volume of cement in the mixture, discouraging reagglomeration by drastically lowering the probability that CNFs will be in close proximity [23-25]. The second method is to use nanoparticles such as 
silica fume to mechanically impede the transport of CNFs through the fresh paste. Yazdanbakhsh showed that CNFs in a cement paste solution without silica fume moved freely, but the addition of silica fume to the mixture allows the CNFs to oscillate in place while preventing translation [20-22].

While silica fume does inhibit CNF transport in fresh cement paste, it is a pozzolan and usually added in mass fractions of $\sim 10 \%$ or less by mass of cement (14\% by volume of cement). Thus, the bulk of the particles present in the fresh paste are OPC and are 1-100 $\mu \mathrm{m}$ in diameter [26]. Larger OPC particles induce a geometric clustering effect that force CNFs to clump together if used in high concentrations. Therefore, it was hypothesized that using a microfine portland cement with a grain size distribution similar to silica fume would have the same stabilization effects of silica fume while simultaneously allowing higher dispersed concentrations of CNFs than an OPC mixture with $10 \%$ silica fume by mass of cement.

The objective of the work reported herein is to determine the effect of using a microfine cement on dispersion of high concentrations of CNFs in PCBMs and the stability of the mixture. The analyses conducted are as follows:

(i) Scanning electron microscopy (SEM) images are obtained to qualitatively examine the dispersion of CNFs among unhydrated cement grains in concentrations up to $5 \%$ by mass of cement.

(ii) A computational simulation of OPC and microfine cement grain size distributions is conducted and their effects on the achievable dispersion of randomly located nanoparticles are quantified.

(iii) A dispersion quantification algorithm utilizing the finite element (FE) method is utilized to quantify CNF dispersion in OPC and microfine cement using SEM images of the unhydrated hybrid cement powders.

(iv) Mortar cube elastic modulus and mortar prism flexural strength measurements for both OPC and microfine hybrid cement mortars are compared to deduce the effect of dispersion on macromechanical properties.

\section{Experimental Equipment and Methods}

2.1. Dispersion Procedure, Materials, and Sonication Setup. This research experiments with concentrations of CNFs up to $5.0 \%$ by mass of cement ( $w t \%$ ) or $10.5 \%$ by volume of cement (vol\%), which required an untraditional method of dispersing the CNFs among the cement grains. Sonicating the CNFs in the PCBM mix water limits the amount of CNFs that can be disentangled due to the fixed volume of the mix water. The authors found empirically that the approximate maximum concentration of CNFs able to be disentangled is $\sim 1 \mathrm{wt} \% \mathrm{CNFs}$ in a mixture with a water-to-cement mass ratio (w/c ratio) of 0.5 . Typical purchased CNFs are initially tangled together in "hairball" structures, and the CNFs fill the aqueous solution as they expand during disentanglement until they form a weak skeletal structure that is not susceptible to sonication efforts, and mechanical mixing during sonication provided no benefit after the structural formation.

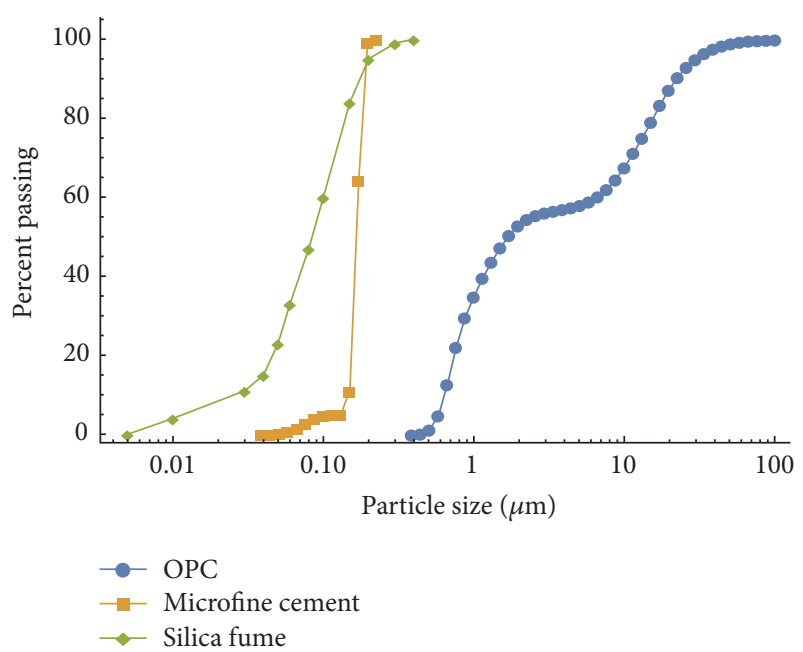

FIGURE 1: Percent passing graph showing the grain size distributions for OPC, microfine cement, and silica fume. The microfine cement has a mostly uniform grain size distribution in the same size range as silica fume, and all grains are smaller than those found in the OPC. The Blaine fineness of the OPC and the microfine cement is $\sim 350 \mathrm{~m}^{2} / \mathrm{kg}$ and $>12,000 \mathrm{~m}^{2} / \mathrm{kg}$, respectively.

Therefore, a method of dispersing high concentrations of CNFs throughout the cement grains was utilized based on the work of Makar et al. [27]. The CNFs were sonicated in pure ethyl alcohol with the cement in relatively low solid-toalcohol concentrations to allow the CNFs to fully disentangle and disperse among the cement grains, and then the alcohol was evaporated using a distillation column to leave behind a premixed hybrid $\mathrm{CNF} /$ cement powder. The hybrid powder was then used in lieu of a typical cement in the mixing process. This dispersion technique is relatively new to the PCBMs industry for producing bulk quantities of material, but it is often used in dispersing nanoparticles through materials like nanofiber-reinforced ceramics $[28,29]$.

The PR-24-XT-PS CNFs purchased from Pyrograf Products, Inc., had diameters of $50-150 \mathrm{~nm}$ and lengths of $50-200 \mu \mathrm{m}$ as purchased. SEM imaging of the hybrid powders was conducted on a Jeol-7700 SEM. The cement types used were a common Type I/II portland cement and a microfine portland cement manufactured by Capitol Cement in San Antonio, TX. The cement grain size distributions are shown in Figure 1 along with that of a typical silica fume for comparison purposes as determined by a Horiba LA-910 particle size analyzer. Table 1 shows no notable difference in oxide composition of the two cement types as determined using a Rigaku Supermini 200 X-ray fluorescence device.

The CNFs were initially sonicated in pure ethyl alcohol for 15 minutes using a Sonics VCX750 sonicator with a CV33 probe at $20 \mathrm{kHz}$ and $40 \%$ amplitude, and then either OPC or microfine cement was added to the alcohol/CNF suspension and further sonicated for an additional 30 minutes. CNFs and cement were added in exact proportions to maintain mass ratios, for example, 2.00 grams of CNFs with 100.0 grams of cement for $2 \mathrm{wt} \%$ CNFs. Mechanical stirring was constantly employed using a Corning PC-353 magnetic stirring plate 
TABLE 1: Pertinent oxide composition of microfine cement and Type I/II cement by percent of total weight indicating similar oxide compositions between the two cement types.

\begin{tabular}{lccccc}
\hline & $\mathrm{SiO}_{2}$ & $\mathrm{Al}_{2} \mathrm{O}_{3}$ & $\mathrm{Fe}_{2} \mathrm{O}_{3}$ & $\mathrm{CaO}_{3}$ & $\mathrm{SO}_{3}$ \\
\hline Microfine & $20.5 \%$ & $5.3 \%$ & $1.7 \%$ & $63.2 \%$ & $4.7 \%$ \\
Type I/II & $20.0 \%$ & $4.9 \%$ & $3.8 \%$ & $62.7 \%$ & $3.4 \%$ \\
\hline
\end{tabular}

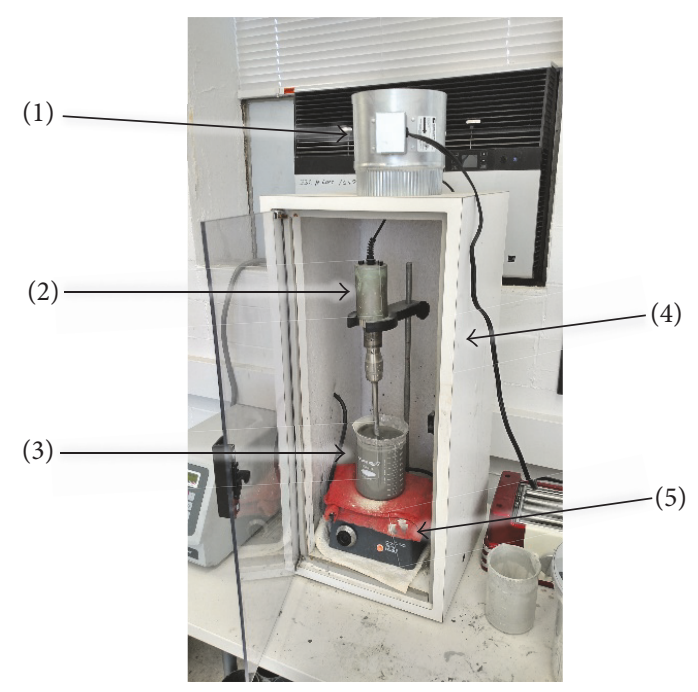

FIGURE 2: Sonication setup showing (1) ventilation fans, (2) sonicator, (3) CNF/cement/alcohol slurry, (4) acoustic noise-reducing cabinet, and (5) magnetic stirring plate.

to encourage an even dispersion throughout the slurry. The complete sonication setup is shown in Figure 2. After sonication, the slurry was poured into a distillation column to remove and recapture the bulk of the alcohol. The material remaining in the distillation column was then transferred to a well-ventilated oven for 24 hours at $105^{\circ} \mathrm{C}$ to ensure that all alcohol was removed. A cement/CNF "cake" was produced in this process that was easily powdered using a metal utensil or a mortar and pestle.

2.2. Quantitative Dispersion Analysis. A unique, nonbiased method was utilized to quantitatively analyze the dispersion of the CNFs in the cementitious matrices [30,31]. In this method, the dispersion parameter is defined based on where a distribution of interest stands between two extrema: fully uniform and fully nonuniform dispersions. The fully uniform dispersion is defined as one in which the mean distance from one particle to its nearest neighbors has a maximum value and the standard deviation of such distances a minimum value. The fully nonuniform dispersion is defined as one in which the mean distance from one particle to its nearest neighbors and the related standard deviation have minimum values, and the particles form a close-packed agglomeration as far as possible from the centroid of the domain to maximize the total distance required to move particles to the fully uniform dispersion. This definition of the fully nonuniform dispersion ensures a dispersion parameter between 0 and 1 for any analyzed domain of partially dispersed discrete particles.
The dispersion of a given set of bodies within a given domain of interest (e.g., CNFs in an SEM micrograph) is quantified based on the minimal amount of work required to move the bodies from their current positions in the domain to the fully uniform state, in comparison to the work required to move the bodies from the fully nonuniform state to the fully uniform state. That is, the amount of work required to move the bodies/particles in the domain of interest to the fully uniform dispersion $\left(S_{i}\right)$ is calculated and normalized by the amount of work required to move the particles in the fully nonuniform dispersion to the fully uniform dispersion $\left(W_{i}\right)$-see Figure 3. The dispersion parameter $(D)$ is then calculated such that a dispersion parameter close to 1 represents a well-dispersed distribution while a dispersion parameter close to 0 represents a poorly dispersed distribution; that is,

$$
D=1-\frac{\sum S_{i}}{\sum W_{i}} \ni 0 \leq D \leq 1
$$

The scalar sum of the distances has an equivalent magnitude to the sum of the work to move the particles since one may assume a force vector with the magnitude of 1 without loss of generality in the calculated dispersion. One may solve for the minimum sum of distances to move the particles by tracking the motion of each individual particle or, in a system of many particles, by tracking the flux of particles in a finite element meshed domain. Note that the absolute length scale of analyzed images is normalized in the dispersion parameter (owing to the ratio); thus, the dispersion parameter used in this research is independent of image scale. A more detailed discussion of the dispersion quantification method and the supporting theory may be found in [30-32]. The dispersion parameter algorithm in this analysis does not account for rotational uniformity and calculates a dispersion parameter based solely on translational uniformity.

One of the goals of this research is to analyze the effect of grain particle size on the dispersion one might obtain for high concentrations of CNFs or other nanoparticles. Since dispersion quantification of the CNFs based on SEM images can be biased depending on the level of magnification, location of image capture, and image clarity, an unbiased computational simulation was conducted to determine the effect on dispersion of a concept called "geometric clustering." The work of Yazdanbakhsh and Grasley demonstrates that there is a maximum achievable dispersion of small filaments throughout a matrix composed of discrete particles-for example, CNF filaments and cement particles $[31,32]$. Geometric clustering occurs due to the fact that CNFs and an unhydrated cement grain cannot cooccupy the same space, and this effect is intensified if the particle size distribution spans several orders of magnitude. 


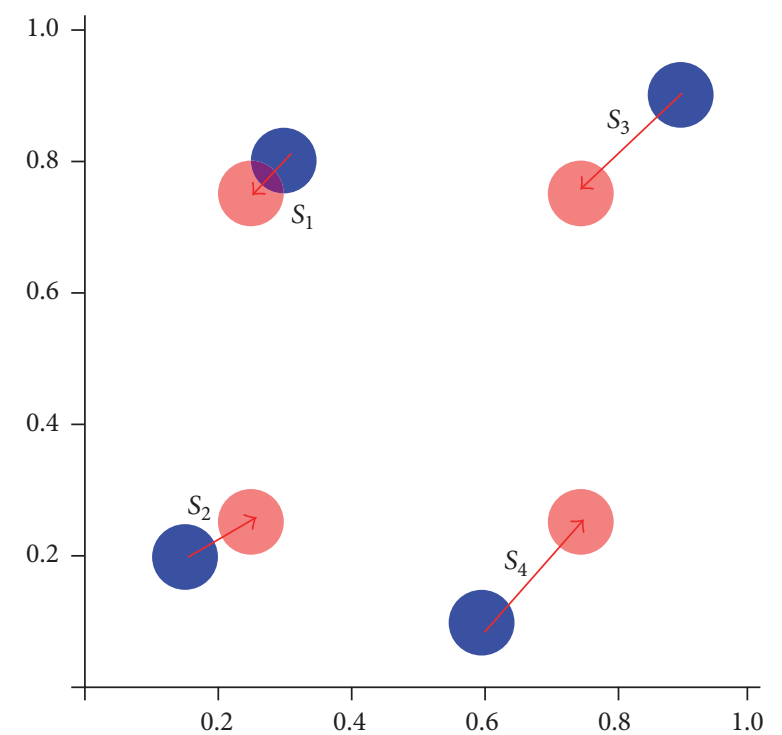

(a)

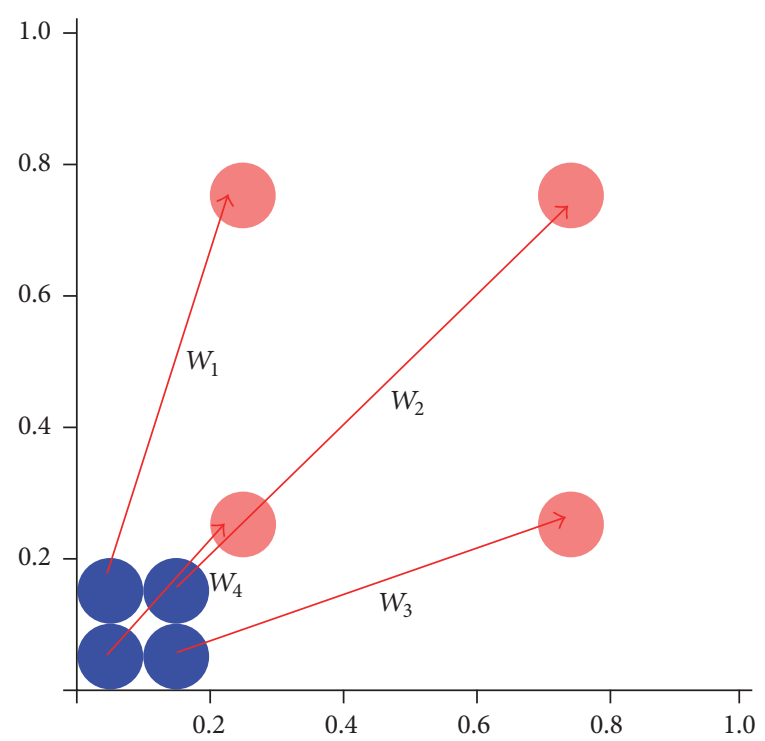

(b)

FIGURE 3: A schematic showing the work vectors to be used in (1). The red circles represent a uniform dispersion. The blue circles in (a) represent a random dispersion. The blue circles in (b) represent a fully nonuniform dispersion. The ratio of $\sum S_{i}$ and $\sum W_{i}$ is used to determine the dispersion parameter.

Figure 4 displays the effect of geometric clustering on the dispersion of nanoparticles due to the particle size distribution of cement grains as determined by the distributions presented in Figure 1. An image of filled circles representing cement grains was generated based on a given circle area fraction of 0.6 with circle radii determined using the particle size distributions presented in Figure 1 and subject to the constraint that no circle could touch or overlap the edge of the image or another circle. The sizes of the images were based on the size of the largest circle; that is, the OPC image frame length shown in Figures 4(a)-4(c) was 3x larger than the diameter of the largest circle. A brute-force algorithm placed the largest circle first utilizing a random-number generator, followed by the second-largest circle, and so on until all circles were placed subject to the aforementioned constraints (Figures 4(a) and 4(d)). Points representing nanoparticle "centroids" were then placed in the open space around the circles subject to the constraint that no point centroid could be placed inside of a circle (Figures 4(b) and 4(e)). Since a defined "centroid" size would create an upper limit to the number of points that could be placed in an image without overlapping the existing cement grain circles, the nanoparticles were graphed as small, filled circles, but mathematically treated as points such that they had no effective size (i.e., the plotted, filled nanoparticle circles could overlap so long as their centroids did not coincide) to more clearly accentuate the geometric clustering effect. A distribution of only the nanoparticles without the cement grain circles (Figures 4(c) and 4(f)) was compared to two other distributions: one in which the same number of points is placed in a hexagonal distribution (fully uniform), and the other in which the same number of points is placed in one spot in the corner of the image (fully nonuniform). In this latter case, since the points had no size, they were all placed at the $(0,0)$ coordinate of the image where $(0,0)$ is the bottom left corner. The dispersion of the points was calculated using (1).

In addition to the $2 \mathrm{D}$ geometric clustering simulations, the finite element based implementation of the dispersion quantification algorithm was performed on multiple SEM images for each concentration of CNFs. For the sake of brevity, the reader is directed to [30-32] for a discussion of implementing FEA for dispersion analysis. It should be noted that if one were to quantify the dispersion in a $3 \mathrm{D}$ domain rather than $2 \mathrm{D}$, the dispersion parameters might change for a given concentration of discrete particles. However, the ranking between different concentrations would remain unaltered. In addition, data received from $2 \mathrm{D}$ simulations and images can give insight to 3D systems but can quantitatively be applied only to $2 \mathrm{D}$ systems; quantitative measurements involving 3D systems must be obtained from 3D models and data sets [33].

\subsection{Mortar Cube Elastic Modulus and Mortar Flexure Prism} Preparation and Testing. Mechanical testing of mortar samples prepared using the hybrid cement types was conducted to determine the effect of the high concentrations of CNFs on the ultimate flexural strength and the relative elastic stiffness of the cementitious mortars. ASTM standards were followed when possible, but the combination of high concentrations of CNFs with a microfine cement required many nonstandard procedures and material proportions. The mortar was proportioned with a w/c ratio of 0.5 and a sand-to-cement mass ratio of 1.75. The ASTM 20-30 Ottawa silica sand used in the mortar mixtures was included primarily to assist in breaking apart clumps of cement during mixing and was specifically chosen for its minimal fines content and minimal absorption capacity. A polycarboxylate high-range water reducing admixture (HRWR) was used in OPC mixtures 


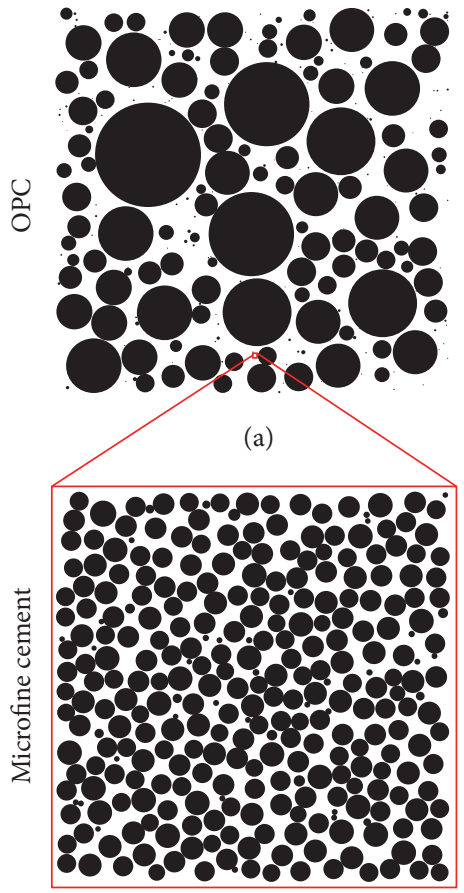

(d)

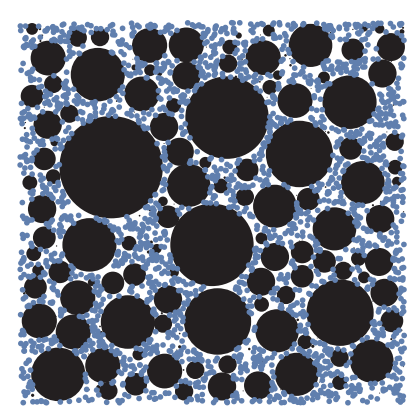

(b)

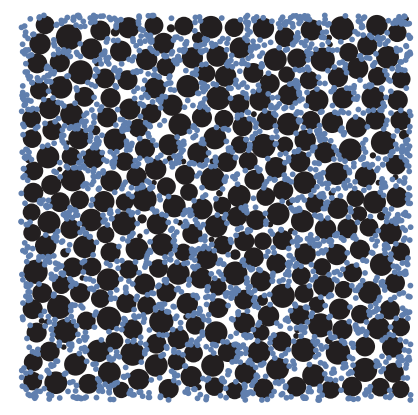

(e)

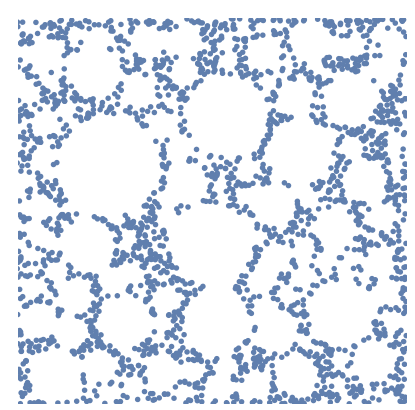

(c)

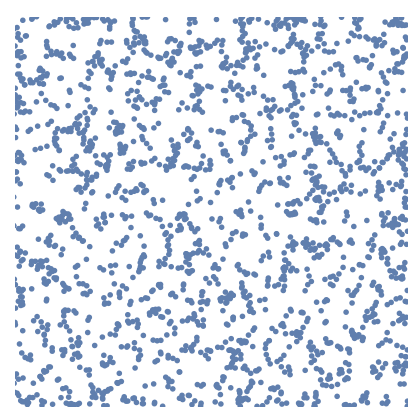

(f)

Figure 4: Examples of the geometric clustering of nanoparticles due to the particle size dispersion of cement grains. (a) A cement grain particle size distribution based on the OPC with a cement grain area fraction of 0.6. (b) The particle size distribution from (a) with 2107 nanoparticle centroids randomly dispersed among the grains. (c) The nanoparticle centroids in (b) without the cement grains from (a) showing the unreinforced regions left from the cement grains. (d) A cement grain particle size distribution based on the microfine cement with a cement grain area fraction of 0.6; a sample size element is placed in (a) that shows the relative size of the images. (e) The particle size distribution from (d) with the same number of nanoparticle centroids in (b) randomly dispersed among the grains. (f) The nanoparticle centroids dispersed in (e) without the cement grains from (d) showing unreinforced regions left by the cement grains, but overall potential dispersion is improved with the use of microfine cement when compared to (c).

with CNFs and in all microfine mixtures. OPC mixtures with $0 \mathrm{wt} \% \mathrm{CNFs}, 1 \mathrm{wt} \% \mathrm{CNFs}, 2 \mathrm{wt} \% \mathrm{CNFs}$, and $3 \mathrm{wt} \% \mathrm{CNFs}$ ( $0 \mathrm{vol} \%, 2.1 \mathrm{vol} \%, 4.2 \mathrm{vol} \%$, and $6.3 \mathrm{vol} \%$, resp.) required $0 \mathrm{wt} \%, 0.1 \mathrm{wt} \%, 0.7 \mathrm{wt} \%$, and $1.3 \mathrm{wt} \%$ HRWR by mass of cement, respectively. Microfine mortar mixtures with $0 \mathrm{wt} \%$ CNFs, $1 \mathrm{wt} \%$ CNFs, $2 \mathrm{wt} \% \mathrm{CNF}$, and $3 \mathrm{wt} \% \mathrm{CNF}$ required $0.8 \mathrm{wt} \%, 1.1 \mathrm{wt} \%, 1.4 \mathrm{wt} \%$, and $1.8 \mathrm{wt} \% \mathrm{HWRW}$, respectively. A sucrose-based chemical retarder was used in the microfine mixtures since the microfine cement sets in less than 5 minutes in ambient conditions without it; all microfine mixtures used $3 \mathrm{wt} \%$ retarder by mass of cement to delay set to approximately 30 minutes. It should be noted that the OPC mixture with $1 \mathrm{wt} \%$ CNFs was, for reasons unclear, susceptible to flash set, so 3-4 drops ( $\sim 0.2$ milliliters) of retarder were added to each kilogram of mortar.

The incorporation of such high concentrations of CNFs and the use of microfine cement required a nonstandard mixing procedure. The water and liquid admixtures were mixed, and then the liquids and sand were placed into the bottom of the mixing bowl in a Hobart N50 mortar mixer. The cement hybrid powder was added and mixed on low for 60 seconds. A metal spatula was used to scrape the sides of the bowl and the mixing paddle to remove any material that may have become congealed. The material was mixed (mixed on low if the material was still solid-like (resembling a powder or individual particles) or on medium/high if the material was liquid-like (a single, malleable mass or a liquid)) for an additional 120 seconds, and then the sides of the mixing bowl and the mixing paddle were scraped again. The material was mixed for an additional 180 seconds, and then the consistency of the material was qualitatively examined. If the mixture was still solidlike, the process was repeated in 120-second mixing intervals until the mixture became fluid for at least 120 seconds. This process could require 11 minutes of mixing for microfine cement with $3 \mathrm{wt} \%$ CNFs. Mortar was placed in the molds in $25 \mathrm{~mm}$ lifts and rodded 75 times per lift with a $6 \mathrm{~mm}$ diameter glass stirring rod, and each lift was vibrated for up to $120 \mathrm{sec}-$ onds per lift. Microfine cement mixtures required 120 seconds of vibration per lift while OPC mixtures required less.

CNFs floated to the top of the hybrid OPC mortar specimens in a layer of foam during vibration as shown in Figure 5. The foam was $\sim 1 \mathrm{~mm}$ and increased up to $\sim 3 \mathrm{~mm}$ in $1 \mathrm{wt} \% \mathrm{CNFs}$ and $3 \mathrm{wt} \%$ CNFs hybrid OPC mortar mixtures, respectively. The foam layer appeared in hybrid OPC mortar specimens but not in the microfine cement mortar specimens, highlighting the instability of the hybrid OPC 


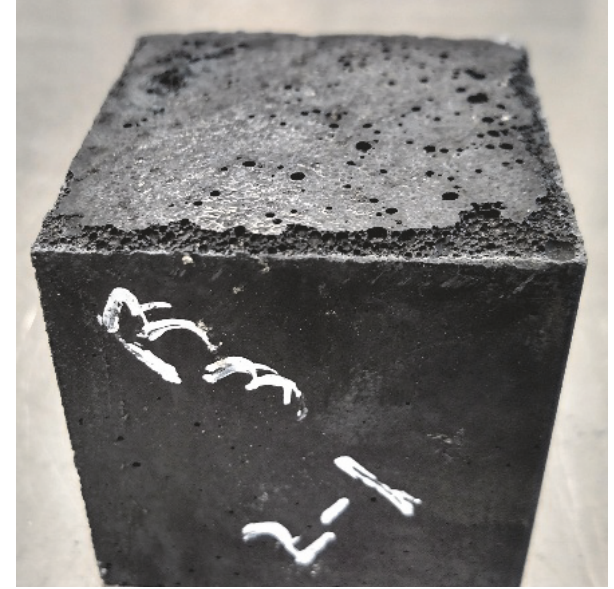

Figure 5: Foam layer as seen on the surface of a $50 \mathrm{~mm} 2 \mathrm{wt} \% \mathrm{CNF}$ OPC hybrid mortar cube.

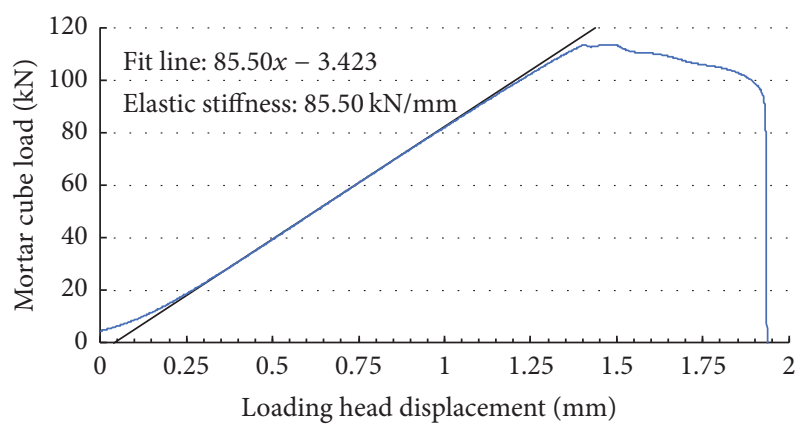

FIGURE 6: Load versus loading head displacement of a mortar cube compression test. Elastic stiffness of the mortar cube was approximated using a fit line through the roughly linear portion of the load versus displacement curve.

mixture and the effectiveness of utilizing small particles (in this case the small cement grains) to stabilize dispersions of CNFs. This observed foam layer has also been seen in other CNF-cement composite research [11].

Mortar samples were prepared for testing at 1 day, 3 days, 7 days, and 28 days. ASTM standards were followed for time of testing; for example, 1-day testing occurred at $24 \pm 0.5$ hours. After $24 \pm 0.5$ hours, the samples were demolded and exposed to $98 \%$ relative humidity $(\mathrm{RH})$ and $23^{\circ} \mathrm{C}$ until time of testing. Three $50 \mathrm{~mm}$ mortar cubes cast using molds described in ASTM C109 were uniaxially compressed for each mixture using a displacement-controlled load frame at a rate of $1 \mathrm{~mm} / \mathrm{min}$ with data points recorded at $20 \mathrm{~Hz}$ [34]. An elastic modulus was approximated via the (roughly) linear portion of the slope of the mortar cube load versus loading head displacement curve as shown in Figure 6. Elastic stiffness results as presented in Section 3.4 are normalized by the control mixture for each cement type rendering the units for elastic stiffness irrelevant.

Two $25 \mathrm{~mm} \times 25 \mathrm{~mm} \times 279 \mathrm{~mm}$ mortar flexure prisms using the molds specified in ASTM C490 were tested for each mixture under a 4-point flexure test apparatus as described in

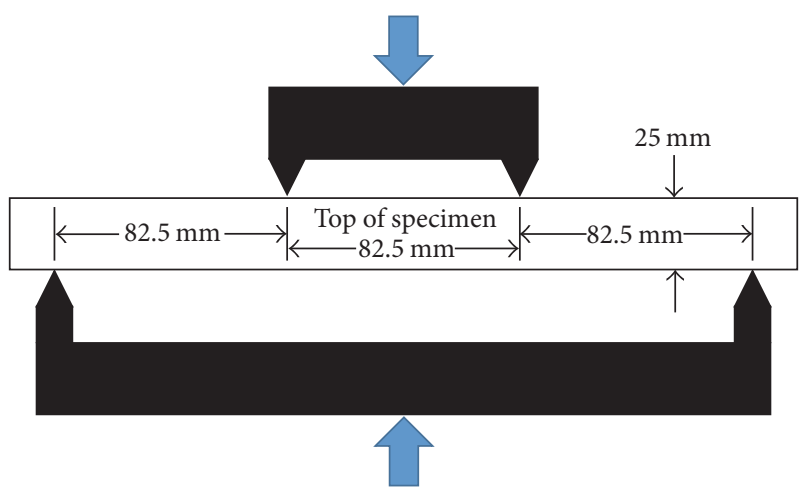

FIGURE 7: Flexure testing schematic. The testing apparatus contacted sides of the specimen that were in contact with the mold, with the top of the specimen at $90^{\circ}$ to the testing plane.

Figure 7 using a compression-controlled load frame at a rate of $1 \mathrm{~mm} / \mathrm{min}$ with data points recorded at $20 \mathrm{~Hz}$ [35]. Flexure specimens were placed in the 4-point flexure apparatus such that the top of the specimens was $90^{\circ}$ to the force plane and the flexure apparatus contacted sides of the specimens that were in contact with the mold; this orientation minimized any error from material settling or bleeding effects that occurred during vibration.

\section{Results and Discussion}

3.1. SEM Images. Initial SEM imaging of the hybrid cement powders revealed that the microfine cement with CNFs had far fewer clumps of CNFs than did the OPC with the same concentrations of CNFs as shown in Figure 8.

At $1 \mathrm{wt} \%$ CNFs (Figures 8(a) and 8(b)), the dispersion is comparable between the OPC and the microfine cement since there are no visible clumps (here we define clumps as consisting of regions with many (at least $10 \mathrm{~s}$ ) of CNFs entangled about each other) of CNFs in either; however, the grains shown in Figure 8(a) are median sizes of the OPC distribution, and none of the larger grains are shown in that particular image. At $2 \mathrm{wt} \% \mathrm{CNF}$, CNF clumping can be seen in the OPC (Figure 8(c)) but not in the microfine cement (Figure $8(\mathrm{~d})$ ); some of the larger cement grains in the OPC are also shown. 3 wt\% CNFs in OPC (Figure 8(e)) show CNFs that are well dispersed among the smaller cement grains of the OPC, but they clump between the larger cement grains. The microfine cement with $5 \mathrm{wt} \%$ CNFs (Figure 8(f)) still shows good dispersion without CNF clumping. There were clumps within the $5 \mathrm{wt} \%$ CNF mixtures (images not shown), but they were sporadic and could likely be minimized in both size and frequency by fine-tuning the applied dispersive effort during sonication.

\subsection{Dispersion of the Computational Simulated Microstruc-} tures. The dispersion of centroids around 2D cement grains, calculated as described in Section 2.2, is presented in Figure 9 for three simulated powder mixtures: nanoparticles with OPC, microfine cement, and pure random nanoparticles with no cement grains. Five images were analyzed per data 
OPC

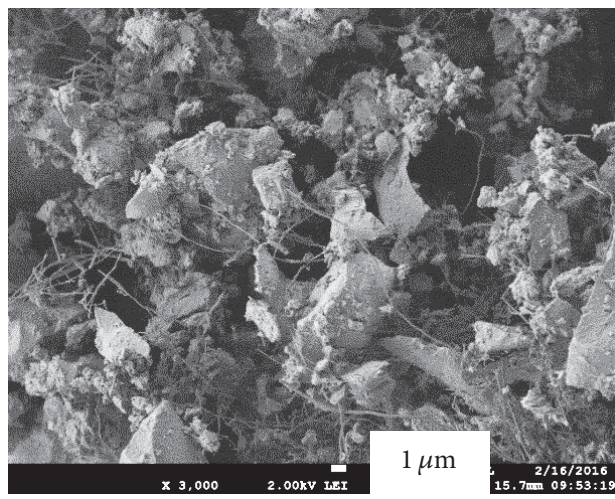

(a)

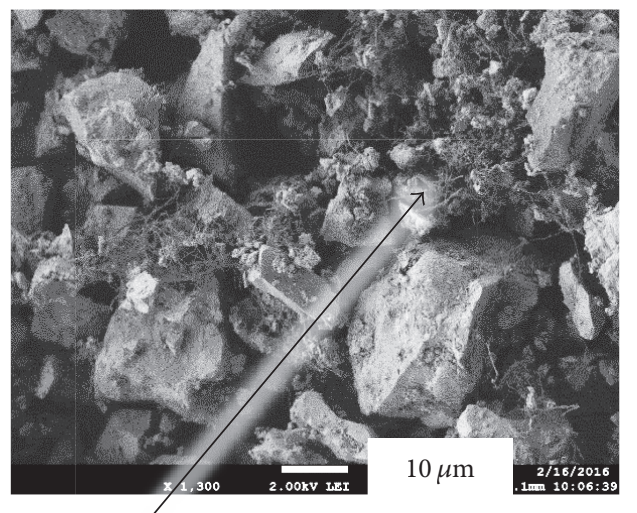

(c)

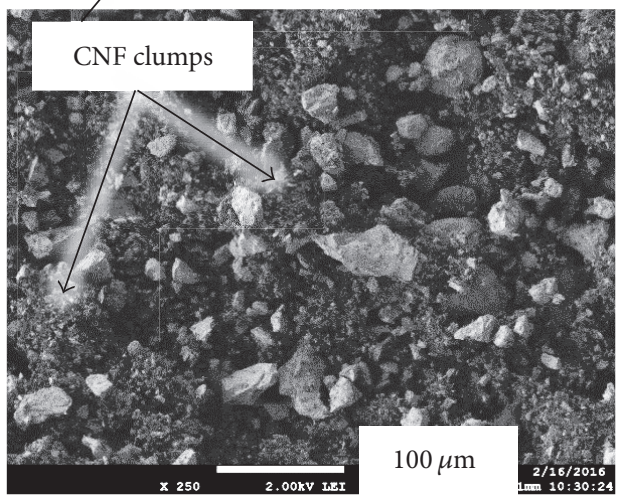

(e)
Microfine cement

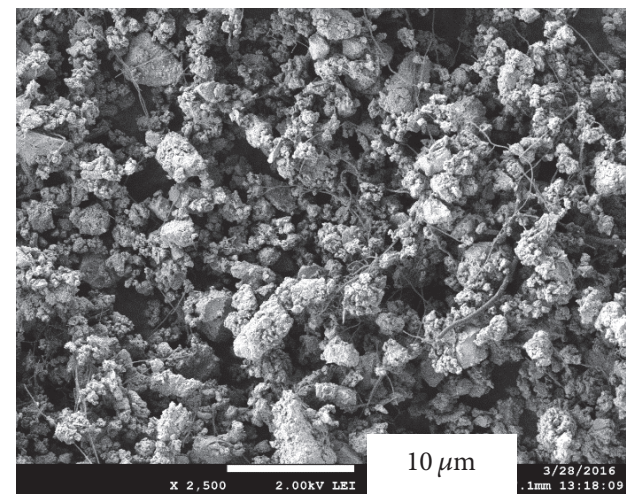

(b)

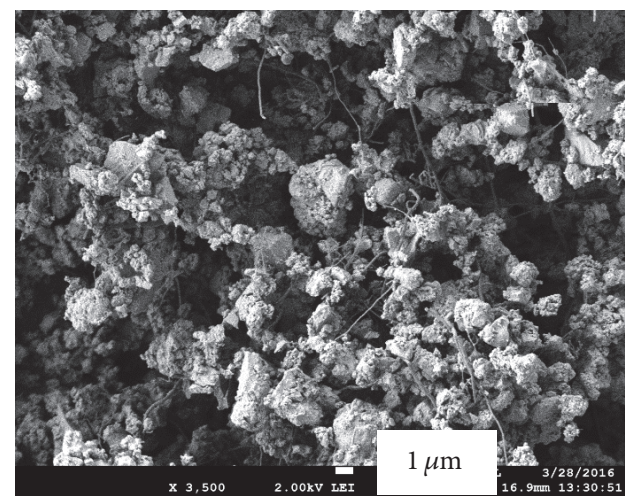

(d)

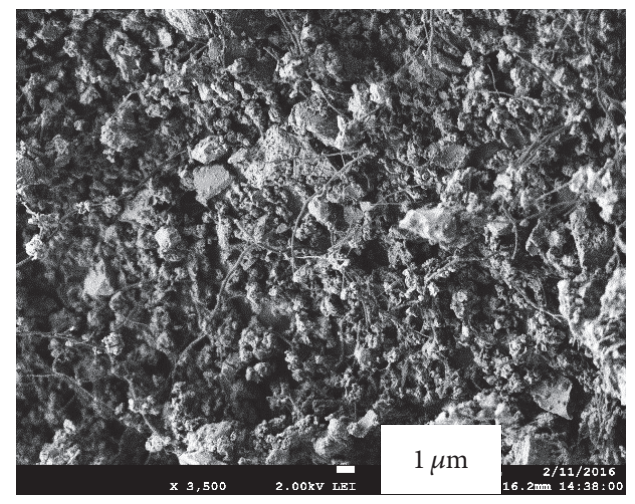

(f)

Figure 8: SEM images of hybrid cement powders. (a) OPC with 1 wt $\%$ CNFs. (b) Microfine cement with 1 wt $\%$ CNFs. (c) OPC with 2 wt $\%$ CNF showing some CNF clumping. (d) Microfine cement with 2 wt\% CNFs showing no CNF clumps. (e) OPC with 3 wt\% CNFs showing severe CNF clumping between the larger cement grains; the regions between the large OPC cement grains are filled with CNF clumps mixed with the smaller cement grains. (f) Microfine cement with $5 \mathrm{wt} \%$ showing no CNF clumping. The cement grain size difference between OPC and microfine is clear. As the concentration of CNFs increases in OPC, the CNF clumping between the larger cement grains becomes more obvious, whereas increasing the concentration of CNFs in the microfine cement does not necessarily lead to CNF clumping.

point. The OPC and microfine cement dispersion parameters are calculated using images similar to those in Figure 4. A drawback of using images similar to those in Figure 4 is that the image scale is not the same for both images-Figure 4(a) has a length scale $80 x$ larger than that of Figure $4(d)$. A comparison of images with the same scale could not be conducted due to computational limitations. Therefore, a "pure random" simulation was created to represent the comparison of OPC and microfine mixtures at the same length scale. The pure random simulation was an image of nanoparticle 


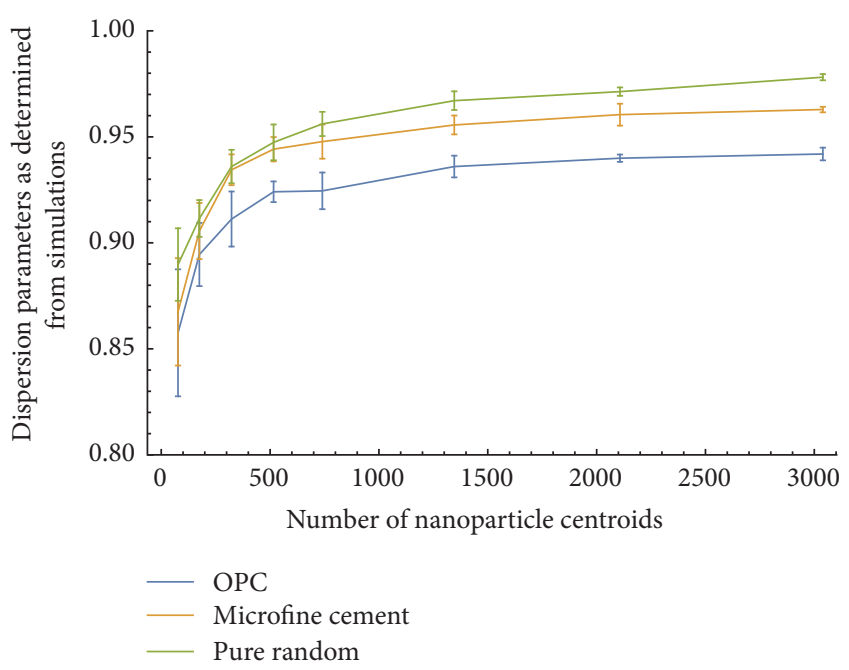

FIGURE 9: Dispersion parameters of computational simulations. The number of centroids in the simulation is shown in the legend on the right side of the image. The dispersion parameter continued to increase for all microstructures, but the dispersion parameter reached closer to 1 in the pure random case since the OPC case was limited by geometric clustering. Error bars are $0.5 *$ range.

"centroids" placed without constraint which is what would have been seen in an image of microfine cement grains with the same length scale as an image of OPC grains. Figure 9 shows that the maximum achievable dispersion parameter for nanoparticles in OPC grains is definitively lower than that for nanoparticles in microfine cement: $0.98,0.96$, and 0.94 for pure random, microfine, and OPC, respectively.

A product of geometric clustering is that the range of the analyses decreased as the number of centroids in the image increased, where range is defined as the difference between the minimum and maximum values. The geometric clustering effect may not be apparent in images with few centroids (in the cases presented herein, less than 100) since the dispersion parameters for each case fall within the others' ranges. In other words, each successive image with new randomly placed centroids can seem to be an image without constraints, resulting in a large range. As the number of centroids increases, each successive image of new randomly placed centroids forms a pattern due to geometric clustering, and the ranges decrease with increasing numbers of centroids in each set of dispersion parameters.

3.3. Dispersion Parameters of SEM Images. The 2D FEimplemented dispersion analysis of multiple SEM images of each dry hybrid material resulted in the dispersion parameters shown in Figure 10. Five images were analyzed per data point. The dispersion parameters for both microfine cement and OPC had similar dispersion parameters at $1 \mathrm{wt} \% \mathrm{CNFs}$. At $2 \mathrm{wt} \% \mathrm{CNFs}$, the dispersion parameter of the microfine cement increased more than for OPC since the OPC dispersion was limited by geometric clustering. At $3 \mathrm{wt} \% \mathrm{CNFs}$, the microfine cement dispersion parameter continued to increase (similar to the trend seen in the computational simulations in

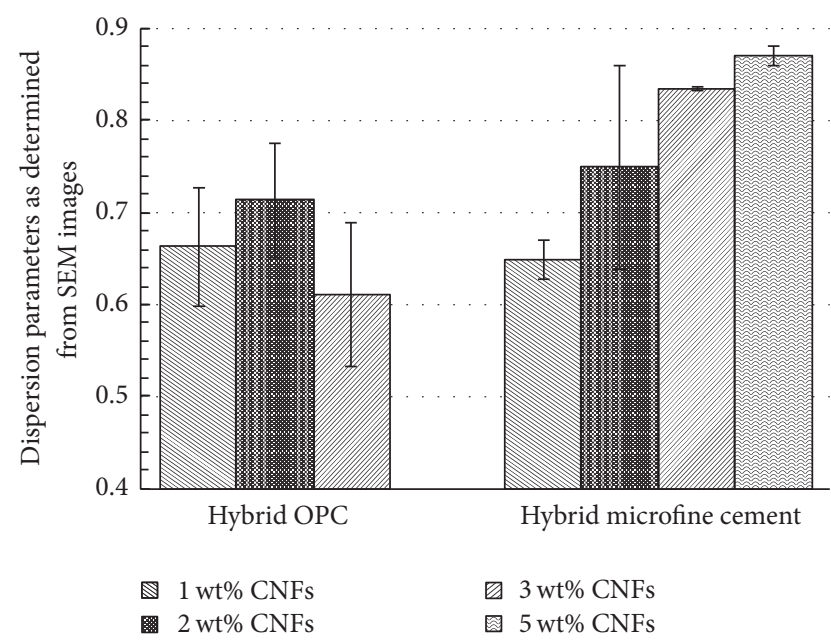

FIGURE 10: 2D FEA results of SEM images. The dispersion parameter for the hybrid microfine cement continued to increase with higher concentrations of CNFs while that of the hybrid OPC eventually reduced due to excessive $\mathrm{CNF}$ clumping. Error bars are $0.5 *$ range.

Section 3.2) while the OPC dispersion parameter decreased due to excessive CNF clumping. SEM imaging in Figure 8 shows that the CNFs can disperse between the smaller OPC grains, but they cannot entangle (wrap around) the larger cement grains. Since the CNFs can only disperse among the smaller cement grains, the apparent CNF concentration is increased in the grains that surround the large OPC grains while remaining at zero in the grains themselves. In addition, the dispersion parameter decreased in this FE analysis due to a limited image size. The image size has a limit since individual CNFs must be able to be seen and traced, and therefore the larger cement grains in the OPC took large portions of the image as seen in Figure 8(c). $5 \mathrm{wt} \%$ CNFs were not attempted in OPC since the CNFs were subject to excessive clumping at 3 wt $\%$ CNFs. The dispersion parameter of hybrid microfine cement continued to increase with $5 \mathrm{wt} \% \mathrm{CNFs}$, quantitatively supporting the hypothesis that the use of microfine cement reduces the geometric clustering effect on CNFs.

The ranges in Figure 10 shed light on the risk of inherent bias and unreliability of using SEM imaging to quantitatively determine dispersion of CNFs in cement grains. The hybrid $\mathrm{OPC}$ results have a range of \pm 0.14 ; this range is a product of the difficulty in finding images without excessively large cement grains. The ranges of the hybrid microfine cement show that the SEM images of the microfine cement can be as biased as the hybrid OPC images; generally, the hybrid microfine dispersion parameter ranges are smaller than those of the hybrid OPC, but the hybrid microfine $1 \mathrm{wt} \%$ dispersion parameter has the largest range in the analysis. This shows the unreliability of using only SEM images without supporting experiments to quantitatively define dispersion in mixtures whose constituents' sizes range over several orders of magnitude.

3.4. Mechanical Testing. The flexure prism ultimate stress and mortar cube elastic moduli for ages 1 day, 3 days, 7 days, 


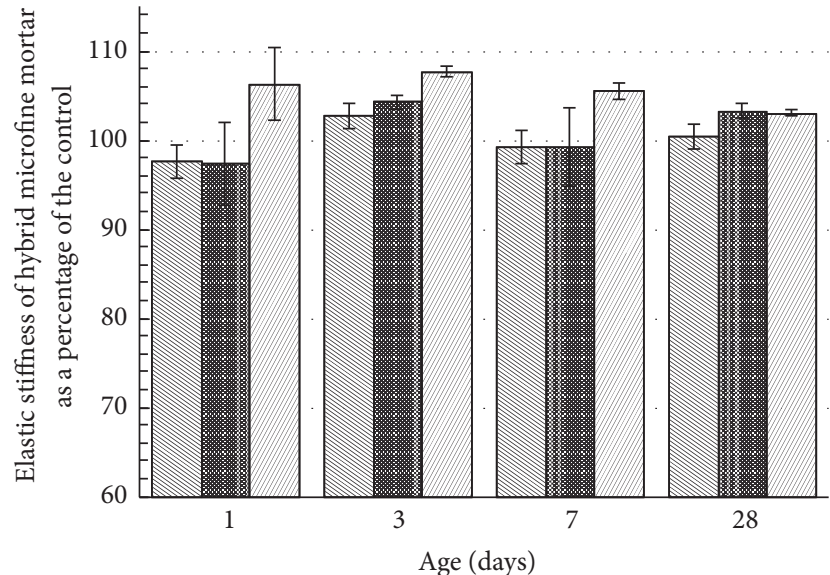

$1 \mathrm{wt} \% \mathrm{CNFs}$

冈 $2 \mathrm{wt} \% \mathrm{CNFs}$

(a)

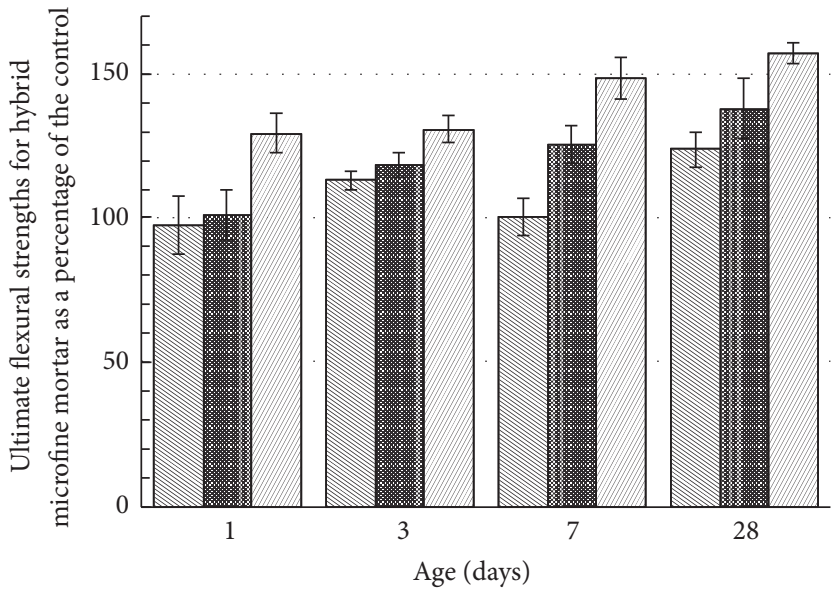

$\mathbb{N} 1 \mathrm{wt} \% \mathrm{CNFs}$

․ $2 \mathrm{wt} \% \mathrm{CNFs}$

(c)

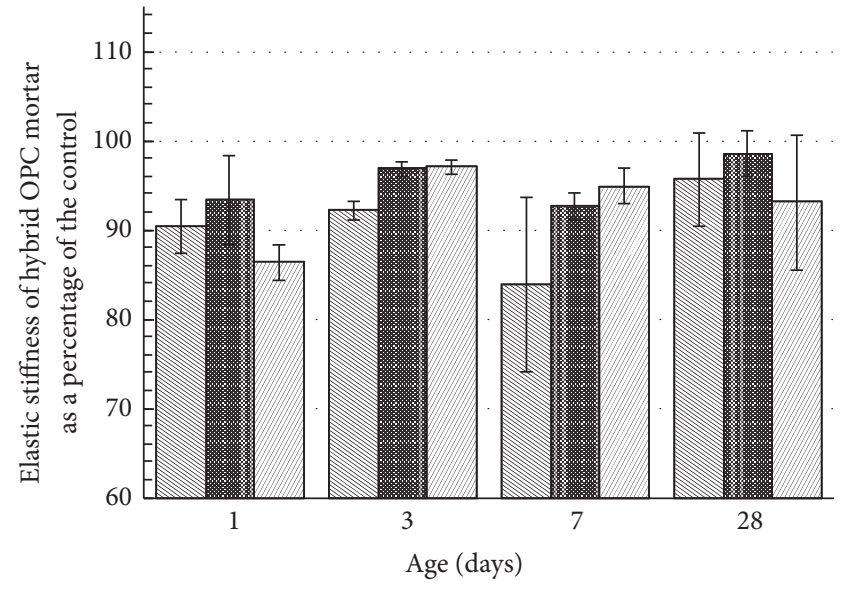

\$ $1 \mathrm{wt} \% \mathrm{CNFs}$

冈 $2 \mathrm{wt} \% \mathrm{CNFs}$

$3 \mathrm{wt} \% \mathrm{CNFs}$

(b)

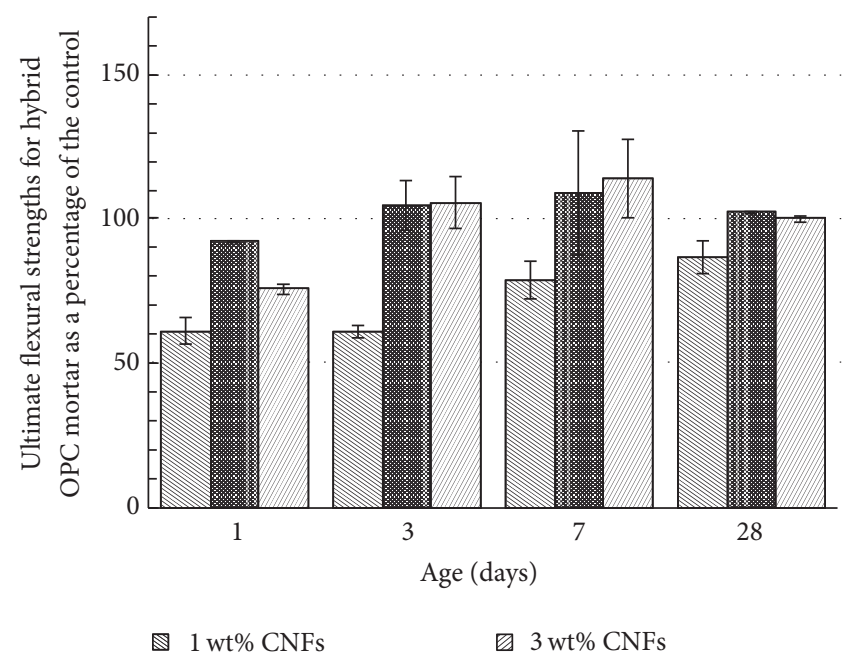

(d)

FIGURE 11: Flexure prism and elastic modulus data for hybrid OPC and microfine mortars normalized by the control. (a) Elastic stiffness of hybrid microfine mortar. (b) Elastic stiffness of hybrid OPC mortar. (c) Ultimate flexural strengths for hybrid microfine mortar. (d) Ultimate flexural strengths for hybrid OPC mortar. Error bars are $0.5 *$ range.

and 28 days at various concentrations of CNFS are shown in Figure 11 as normalized by the control; that is, a value of $100 \%$ indicates that the specimen had the same stiffness/flexural strength as the specimen without CNFs. The elastic stiffness of the hybrid microfine mortar shown in Figure 11(a) was not significantly impacted and remained within $8 \%$ of the control specimens. The elastic stiffness of hybrid OPC mortar shown in Figure 11(b) revealed no specific trend, but $75 \%$ of specimens had a lower stiffness than the control mixture. The hybrid microfine cement flexural prisms in Figure 11(c) showed a definitive trend that increasing the concentration of CNFs increases the ultimate flexural strength by up to $50 \%$. The hybrid OPC flexural prism strengths shown in
Figure $11(\mathrm{~d})$ indicate a reduced strength versus the control for $1 \mathrm{wt} \%$ CNFs addition while $2 \mathrm{wt} \%$ and $3 \mathrm{wt} \%$ addition of CNFs indicate a comparable strength to the control after a time of 3 days.

The mechanical tests of mortar flexure prisms and compression cubes reinforce the proposition that the dispersion of CNFs is improved in the hybrid microfine cement versus the hybrid OPC. The hybrid OPC had CNF clumping issues, especially at concentrations above $1 \mathrm{wt} \% \mathrm{CNF}$, and the flexural strengths and elastic moduli of the hybrid OPC mortar were often lower than the control specimens. CNFs in the microfine hybrid mortar often increased flexural strengths and had inconsistent but inconsequential effects on the elastic 
modulus, suggesting that the hybrid microfine cement mortar did not have clumping issues and had a more stable dispersion of CNFs.

\section{Conclusions}

This research documents the effect of cement particle size distribution on the dispersion of CNFs in cementitious materials. Unprecedented high concentrations of CNFs up to $3 \mathrm{wt} \%$ and $5 \mathrm{wt} \%$ (by mass of cement) were tested in OPC and microfine cement mixtures, respectively, and results indicate the following conclusions:

(i) Dispersing CNFs among cement grains using the alcohol/sonication/distillation technique provided excellent dispersion of CNFs among the microfine cement at concentrations up to $5 \mathrm{wt} \%$ by mass of cement.

(ii) Geometric clustering of nanoparticles due to the size of the cement grains creates a definitive difference in dispersion parameters between 2D OPC and microfine cement simulations, with microfine cement having a higher achievable level of dispersion. The range in $2 \mathrm{D}$ geometric clustering simulations substantially decreased with the addition of more nanoparticles, proving that geometric clustering has more impact as the concentration of nanoparticles increases.

(iii) Hybrid OPC is susceptible to excessive clumping of CNFs between large cement grains at concentrations above $1 \mathrm{wt} \%$ CNFs, while CNFs showed only sporadic clumping in hybrid microfine cement at concentrations up to $5 \mathrm{wt} \%$ CNFs. Dispersion analysis of SEM imaging utilizing an FEA algorithm revealed that the excessive CNF clumping in OPC can hinder dispersion. The large ranges of the dispersion parameters determined from the SEM images suggested that SEM imaging is susceptible to bias when calculating quantitative information.

(iv) Mechanical testing revealed that concentrations of CNFs up to $3 \mathrm{wt} \%$ in OPC mortar resulted in reductions in mortar elastic stiffness or flexural strength in over $60 \%$ of the specimens with the remaining specimens showing no definitive change in performance. Concentrations of CNFs up to $3 \mathrm{wt} \%$ in microfine mortar had inconsequential effects $( \pm 8 \%)$ on mortar elastic stiffness and increased flexural strength up to $50 \%$ from the control mixture with 3 wt $\%$ CNFs at 28 days.

(v) The segregation of CNFs out of the hybrid OPC mortar during specimen compaction and vibration revealed that hybrid OPC had an unstable dispersion of CNFs while hybrid microfine cement mortar had a stable dispersion of CNFs. While geometric clustering does affect dispersion, the primary reason-in the authors' opinion-for the superior mechanical properties of the hybrid microfine mortar mixtures over the hybrid OPC mortar mixtures is the stability of the hybrid microfine mixture.

\section{Disclosure}

Joshua Hogancamp is the primary author.

\section{Conflicts of Interest}

The authors declare that there are no conflicts of interest regarding the publication of this paper.

\section{Acknowledgments}

The authors thank Capitol Cement in San Antonio, TX, for providing the microfine cement and Grace Admixtures for providing the chemical admixtures. Use of the Texas A\&M Materials Characterization Facility is acknowledged.

\section{References}

[1] D. D. L. Chung, "Cement reinforced with short carbon fibers: a multifunctional material," Composites Part B: Engineering, vol. 31, no. 6-7, pp. 511-526, 2000.

[2] F. Sanchez and K. Sobolev, "Nanotechnology in concrete-a review," Construction and Building Materials, vol. 24, no. 11, pp. 2060-2071, 2010.

[3] P.-W. Chen and D. D. L. Chung, "Concrete reinforced with up to 0.2 vol\% of short carbon fibres," Composites, vol. 24, no. 1, pp. 33-52, 1993.

[4] D. Zhang, Q. Wang, and S. Xu, "Experimental study on electric properties of carbon fiber reinforced concrete," Journal of Wuhan University of Technology-Materials Science Edition, vol. 22, no. 3, pp. 546-550, 2007.

[5] S. J. Chen, F. G. Collins, A. J. N. Macleod, Z. Pan, W. H. Duan, and C. M. Wang, "Carbon nanotube-cement composites: a retrospect," The IES Journal Part A: Civil and Structural Engineering, vol. 4, no. 4, pp. 254-265, 2011.

[6] S. Parveen, S. Rana, and R. Fangueiro, "A review on nanomaterial dispersion, microstructure, and mechanical properties of carbon nanotube and nanofiber reinforced cementitious composites," Journal of Nanomaterials, vol. 2013, Article ID 710175, 19 pages, 2013

[7] Y. L. M. Di Gao and L. M. Pend, "Mechanical and electrical properties of carbon-nanofiber self-consolidating concrete," in Earth and Space 2010, pp. 2577-2585, American Society of Civil Engineers, 2010.

[8] D. Gao, M. Sturm, and Y. L. Mo, "Electrical resistance of carbonnanofiber concrete," Smart Materials and Structures, vol. 20, no. 4, Article ID 049501, 2011.

[9] A. Yazdanbakhsh, Z. Grasley, B. Tyson, and R. Abu Al-Rub, "Challenges and benefits of utilizing carbon nanofilaments in cementitious materials," Journal of Nanomaterials, vol. 2012, Article ID 371927, 8 pages, 2012.

[10] Q. Li, J. Liu, and S. Xu, "Progress in research on carbon nanotubes reinforced cementitious composites," Advances in Materials Science and Engineering, vol. 2015, Article ID 307435, 16 pages, 2015.

[11] F. Sanchez and C. Gay, "Performance of carbon nanofibercement composites with a high-range water reducer," Transportation Research Record, vol. 2142, no. 1, pp. 109-113, 2010. 
[12] L. Brown and F. Sanchez, "Influence of carbon nanofiber clustering on the chemo-mechanical behavior of cement pastes," Cement and Concrete Composites, vol. 65, pp. 101-109, 2016.

[13] F. Sanchez, L. Zhang, and C. Ince, "Multi-scale performance and durability of carbon nanofiber/cement composites," in Proceedings of the 3rd International Symposium on Nanotechnology in Construction, pp. 345-350, Prague, Czech Republic, 2009.

[14] A. Yazdanbakhsh, Z. Grasley, B. Tyson, and R. K. Abu Al-Rub, "Distribution of carbon nanofibers and nanotubes in cementitious composites," Transportation Research Record, vol. 2142, pp. 89-95, 2010.

[15] X.-L. Xie, Y.-W. Mai, and X.-P. Zhou, "Dispersion and alignment of carbon nanotubes in polymer matrix: a review," Materials Science and Engineering: R: Reports, vol. 49, no. 4, pp. 89-112, 2005.

[16] V. Šmilauer, P. Hlaváček, and P. Padevět, "Micromechanical analysis of cement paste with carbon nanotubes," Acta Polytechnica, vol. 52, no. 6, pp. 22-28, 2012.

[17] M. S. Konsta-Gdoutos, Z. S. Metaxa, and S. P. Shah, "Highly dispersed carbon nanotube reinforced cement based materials," Cement and Concrete Research, vol. 40, no. 7, pp. 1052-1059, 2010.

[18] N. Yazdani and V. Mohanam, "Carbon nano-tube and nanofiber in cement mortar: effect of dosage rate and water-cement ratio," International Journal of Material Sciences, vol. 4, no. 2, p. 45, 2014.

[19] Z. S. Metaxa, M. S. Konsta-Gdoutos, and S. P. Shah, "Nanoimaging of highly dispersed carbon nanotube reinforced cement based," in Proceedings of the 7th International RILEM Symposium on Fibre Reinforced Concrete: Design and Applications, pp. 125-131, Rilem Publications, Chennai, India, 2008.

[20] C. Stephens, L. Brown, and F. Sanchez, "Quantification of the re-agglomeration of carbon nanofiber aqueous dispersion in cement pastes and effect on the early age flexural response," Carbon, vol. 107, pp. 482-500, 2016.

[21] A. Yazdanbakhsh and Z. Grasley, "Utilization of silica fume to stabilize the dispersion of carbon nanofilaments in cement paste," Journal of Materials in Civil Engineering, vol. 26, no. 7, pp. 1-10, 2014.

[22] F. Sanchez and C. Ince, "Microstructure and macroscopic properties of hybrid carbon nanofiber/silica fume cement composites," Composites Science and Technology, vol. 69, no. 7-8, pp. 1310-1318, 2009.

[23] M. S. Konsta-Gdoutos, Z. S. Metaxa, and S. P. Shah, "Multi-scale mechanical and fracture characteristics and early-age strain capacity of high performance carbon nanotube/cement nanocomposites," Cement and Concrete Composites, vol. 32, no. 2, pp. 110-115, 2010.

[24] Z. S. Metaxa, M. S. Konsta-Gdoutos, and S. P. Shah, "Carbon nanofiber cementitious composites: effect of debulking procedure on dispersion and reinforcing efficiency," Cement and Concrete Composites, vol. 36, no. 1, pp. 25-32, 2013.

[25] E. E. Gdoutos, M. S. Konsta-Gdoutos, P. A. Danoglidis, and S. P. Shah, "Advanced cement based nanocomposites reinforced with MWCNTs and CNFs," Frontiers of Structural and Civil Engineering, vol. 10, no. 2, pp. 142-149, 2016.

[26] S. Mindess, F. J. Young, and D. Darwin, Concrete, Pearson Education, 2nd edition, 2003.

[27] J. M. Makar, J. C. Margeson, and J. Luh, "Carbon nanotube cement composites-early results and potential applications," in Proceedings of the 3rd International Conference on Construction
Materials: Performance, Innovations and Structural Implications, pp. 1-10, Vancouver, Canada, 2005.

[28] L. Feng, N. Xie, and J. Zhong, "Carbon nanofibers and their composites: a review of synthesizing, properties and applications," Materials, vol. 7, no. 5, pp. 3919-3945, 2014.

[29] P. Hvizdoš, V. Puchý, A. Duszová, and J. Dusza, "Carbon nanofibers reinforced ceramic matrix composites," in Nanofibers-Production, Properties and Functional Applications, D. T. Lin, Ed., InTech, Rijeka, Croatia, 2011.

[30] A. Yazdanbakhsh, Z. Grasley, B. Tyson, and R. K. Abu Al-Rub, "Dispersion quantification of inclusions in composites," Composites Part A: Applied Science and Manufacturing, vol. 42, no. 1, pp. 75-83, 2011.

[31] A. Yazdanbakhsh and Z. Grasley, "The theoretical maximum achievable dispersion of nanoinclusions in cement paste," Cement and Concrete Research, vol. 42, no. 6, pp. 798-804, 2012.

[32] Z. C. Grasley and A. Yazdanbakhsh, "Quantifying the dispersion of discrete inclusions in composites using continuum theory," Composites Part A: Applied Science and Manufacturing, vol. 42, no. 12, pp. 2043-2050, 2011.

[33] S. Meille and E. J. Garboczi, "Linear elastic properties of models of porous materials," Modeling and Simulation in Materials Science and Engineering, vol. 9, no. 5, pp. 371-390, 2001.

[34] ASTM, "ASTM C109: Standard Test Method for Compressive Strength of Hydraulic Cement Mortars," ASTM International, 2016.

[35] ASTM, "ASTM C490: Standard Practice for Use of Apparatus for the Determination of Length Change of Hardened Cement Paste, Mortar, and Concrete," ASTM International, 2011. 

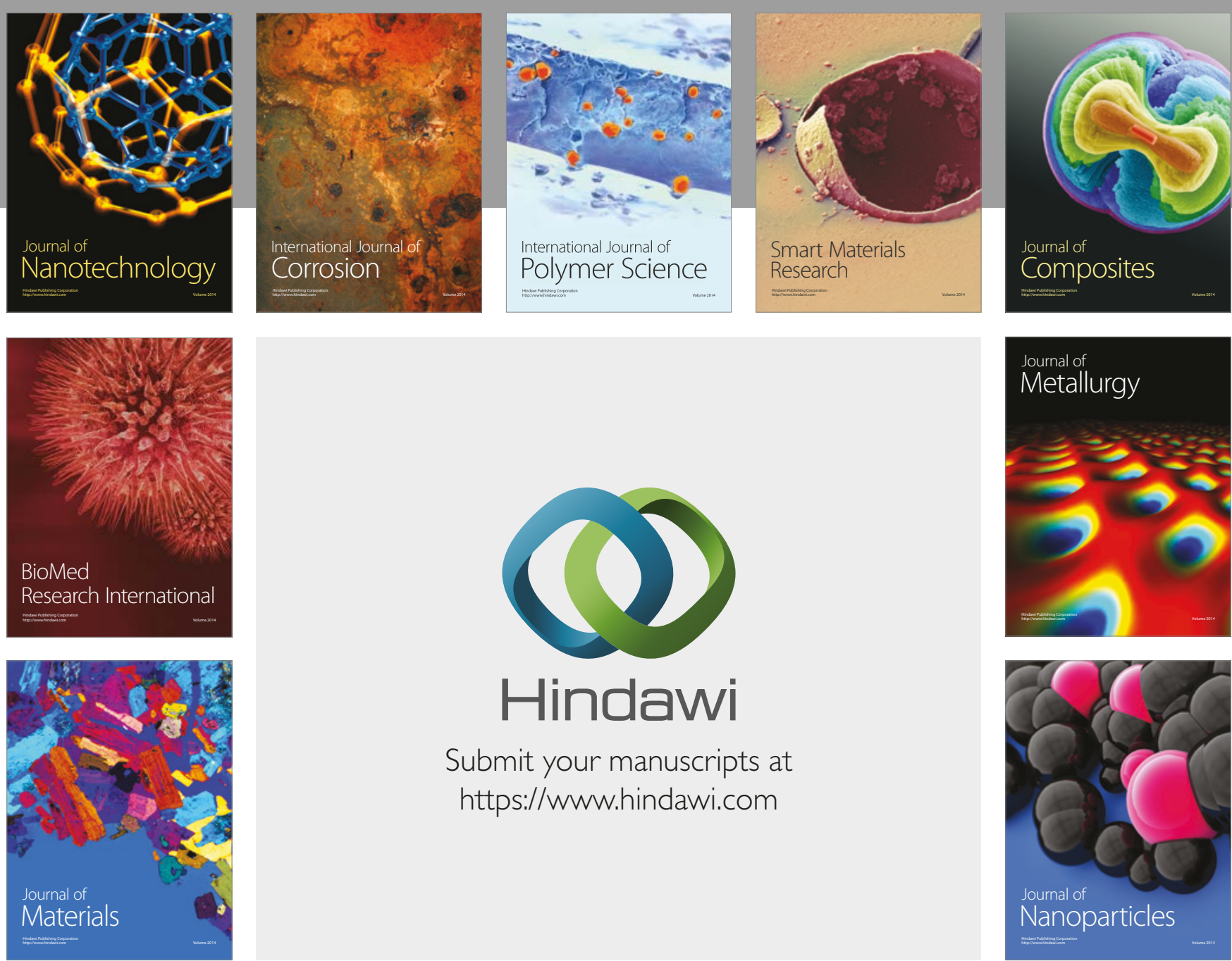

\section{Hindawi}

Submit your manuscripts at

https://www.hindawi.com
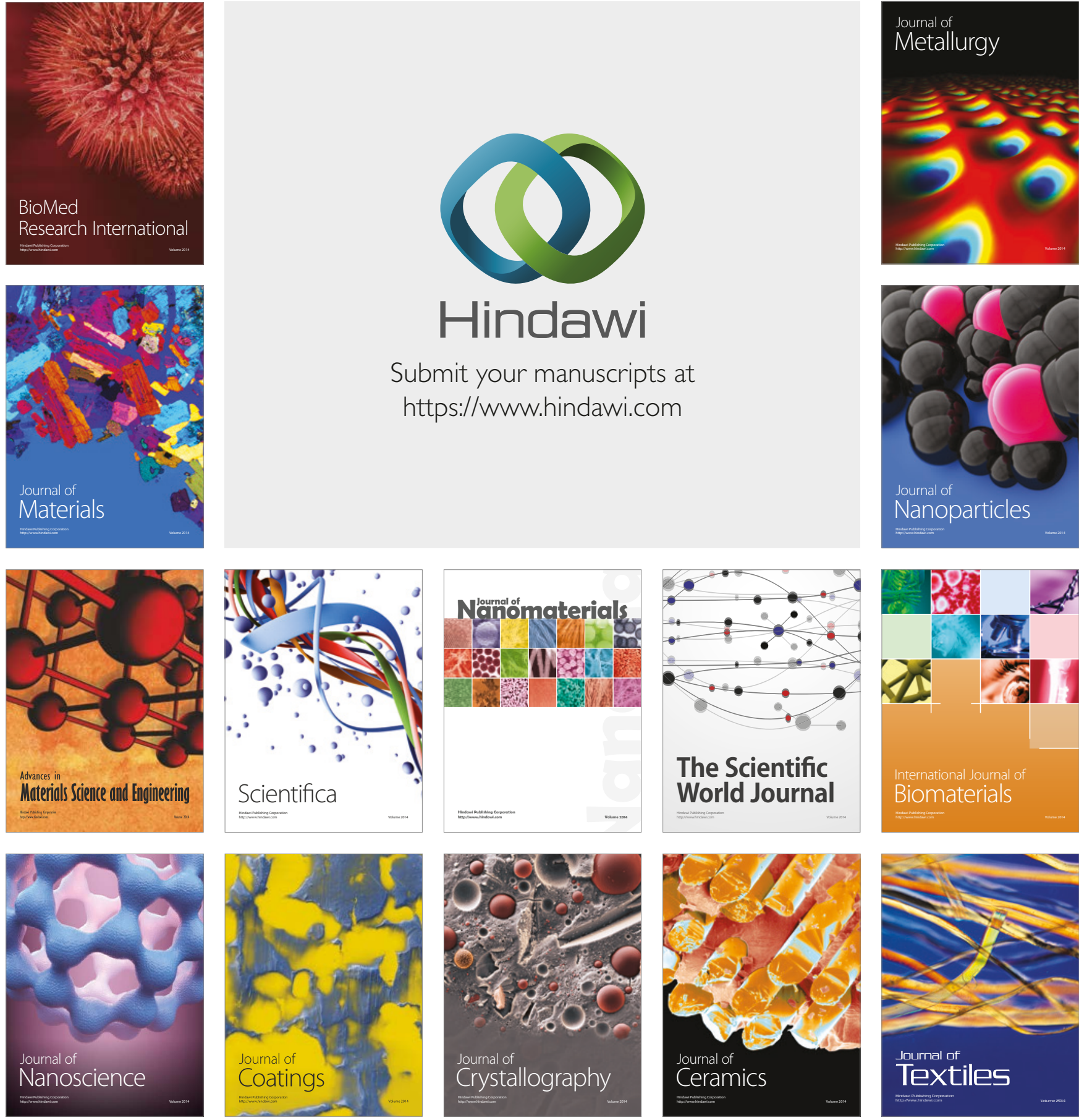

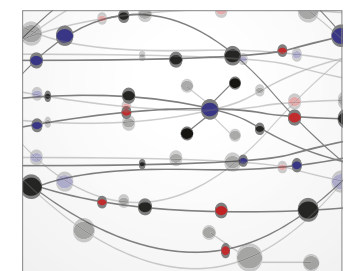

The Scientific World Journal
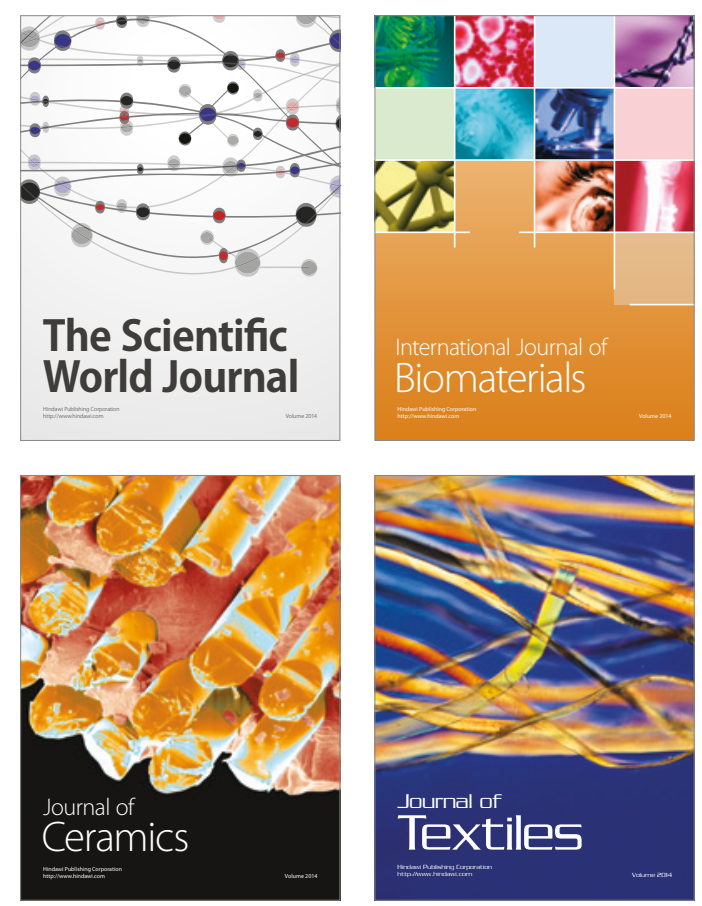